\title{
The Forest That Walks: Digital Fieldwork and Distributions of Site
}

\begin{abstract}
Walking is a practice that often centers humans as moving and experiencing subjects. Whether on solitary rambles or in collective social and political engagements, people are central to understanding places on the move. However, multiple organisms and environments are also involved in moving practices. This article decenters human movement to ask: How does the forest walk? In a time when forest sites might also be inaccessible to multiple people who are remote from forest locations, this article further considers how digital fieldwork becomes a way to tune into moving forests and the relations they activate and sustain. Digital technologies differently constitute and mobilize environments in ways that can have consequences for how forests and people move, and for how environmental change is configured and addressed.
\end{abstract}

\section{Keywords}

forests, smart forests, walking, digital media, digital fieldwork, environmental change

Walking has generated multiple narratives that unfold through the musings of a single body in motion. Within these studies, the sensing human body becomes a mobile observation platform, gathering experiences and forming impressions that generate compilations of site (Edensor, 2000; O'Rourke, 2013). In a different way, practices of walking together, whether through researching and conversing or through marching, protesting, and collectively organizing, increasingly feature within studies of social life and social movements (Bates \& Rhys-Taylor, 2017; Springgay \& Truman, 2017). From environmental protests against contaminated landfills in Warren County, North Carolina (Bullard, 1990), to silent marches, including of protestors seeking justice for Grenfell Tower victims in London, ${ }^{1}$ people moving and walking together can further activate environmental engagements and forms of storytelling that seek to transform unjust conditions (Houston, 2013; Lessard et al., 2021). But how do sites, including many organisms that compose environments, also walk and form collectives? Moreover, how do digital technologies differently mobilize environments through remote and distributed engagements that reconstitute walking?

These questions are initially spurred by one particular form of collective walking in Chile. Here, Atacameño Indigenous leaders protesting lithium mining in the Atacama region walked over 350 kilometers to the regional capital, Antofagasta. They referred to their protest as "the desert that walks." ${ }^{2}$ These walkers carried the desert with them as they protested against lithium extraction in Chile, where $40 \%$ of the world's lithium is located. The desert mobilized their journey and became present as another way of inhabiting the land beyond extractivism. The desert further circulated through different forms of media as it became part of a larger environmental campaign. It also traveled through the circuits of extraction that mine, distribute, and recompose desert materials along global supply chains, and the multiple forms of monitoring that would track the movement of these "resources." These different desert walks show how collectives can form through the process of movement.

In a parallel way and across different locations, this article investigates the forest that walks. While there has been much emphasis on bipedal humanoids walking against a backdrop of the world around them, this article seeks to decenter and transform this usual diagram of human movement. Instead, this investigation considers more-thanhuman mobilities and distributions of site, especially in relation to digital technologies and how they activate and

'University of Cambridge, UK

Corresponding Author:

Jennifer Gabrys, Chair in Media, Culture and Environment, University of Cambridge, 16 Mill Lane (Top Floor), Cambridge CB2 ISB, UK.

Email: jg899@cam.ac.uk 
access environments. The aim of this article is twofold: (a) to consider the relative more-than-human and forest-based vectors of movement in relation to existing walking scholarship, as a way of characterizing sensation and movement, and (b) to investigate how digital technologies co-constitute and mobilize forests as distributed sites that travel across platforms, data sets, observation technologies, and participatory apps.

This research is part of the Smart Forests project that studies the consequences of the increasing digitalization of forest environments. ${ }^{3}$ It develops in part as an inquiry into forests and technologies. It also works toward an emergent form of digital fieldwork that unfolds in the context of inaccessible sites, whether due to COVID-19 and travel restrictions, or due to geopolitical conflict, extraction and violence, securitization, territorial restrictions, and infectious diseases. How is it possible to find other ways to walk with the forest, in a time when it can be difficult to walk to and in the forest? By working with the example of the Global Forest Watch (GFW) platform and app, I consider how forests walk, whether through digital tools for observing their movement, tracking supply chains, or receiving alerts that remind various actors to return to forests to detect and act on environmental change. The point here is not to stretch walking into an amorphous analytic but to consider how it is a cascade of relations through which entities and worlds mobilize and are mobilized (Sundberg, 2014). These relations, moreover, can be activated through decentering humans as situated within specific places. Such a realignment can draw attention to the way of knowing and being in sites that also overlook other forest inhabitations, from Indigenous experience and cosmologies to more-than-human relations, which are often rendered less significant when addressing environmental change.

\section{Organisms and Environments on the Move}

Forests are on the move. Yet their shifting patterns are more or less detectable to forest dwellers or urbanites, sensors or satellites. Increasing temperatures, collapsing biodiversity, expanding development, and dispossession of Indigenous people contribute to changing forms and formations of forest spaces. Worldwide, forests are declining; they are receding by millions of hectares every year due to deforestation. In some places, however, forests are expanding due to climate change. ${ }^{4}$ This restless, often destructive movement in turn informs the movements of multiple organisms and forest dwellers, including where or whether they can move within forest spaces. When forests move, they do so with multiple other entities. Their movements transform how other organisms can travel. The forest walks through environmental change and across remote-sensing satellites. It is transported through in situ engagements, as well as stories and digital dashboards that would narrate and monitor shifting forest inhabitations.

Despite the movements of ecosystems and organisms, as well as atmospheric and oceanic currents, walking is most often reserved as a practice that describes human movement. Within walking literature, the individual human (and often White privileged male) bipedal body has dominated as a figure of movement, with environments, organisms, and other people often playing the role of scenic backdrop to heroic endeavors (Cadogan, 2016; Springgay \& Truman, 2019). These movements at times have been characterized in a register of flânerie, where an untethered human drifts within typically urban spaces gathering impressions but remaining relatively detached from the conditions through which movement occurs (Benjamin, 1999). Such accounts often focus on individual sensation, where walking and movement create a cinema of the self in urban or wild spaces. Accounts of walking and thinking also abound, with the emphasis placed on working out ideas through often solitary movement, or grappling with states of inner torment by remaining in motion (Gros, 2009/2014).

At the same time, increasingly there is more attention to walking as a collective action. Walking with others can take multiple forms, from marching and protest to research and inquiry. Within the area of environmental and social justice, demonstrations and protests become crucial ways to take up and transform spaces. The gathering of people can disrupt traffic, remake urban circulation, transform everyday patterns, and introduce different practices and exchanges that can alter the spaces within which walking occurs. In what is often referred to as a moment that launched environmental justice as a more consolidated movement in 1982, protesters fighting against illegal dumping of polychlorinated biphenyl, or PCB-contaminated soil in Warren County, North Carolina, marched arm-in-arm on highways, faced off with heavy equipment dumping soil in landfills, and lay on roadways to stop operations (Pezzullo, 2007). In a different but resonant way, walking and marching as practices have characterized multiple social movements, from Black Lives Matter to climate strikes to the Grenfell silent walks in London protesting the U.K. government's lack of response to the tragic fire that destroyed high-rise housing with flammable cladding and led to the deaths of 72 people. By walking together, people express a sense of shared struggle and reflection. Walking can then activate solidarity through collective movement.

Walking can also be a formative part of fieldwork, research, and inquiry, whether undertaken individually or collectively (Gabrys, 2012). In this way, the Citizen Sense project has worked with communities to install sensors for tuning in to air pollution from industry, traffic, and construction. Walks form a critical part of this research, which involves collectively identifying where to sense pollution, 
as well as how to develop strategies for environmental intervention and transformation (Gabrys, 2017, forthcoming). Walking as research can be a way to demonstrate the distributions of data or spatial unfoldings of algorithms (Powell, 2018; Ziewitz, 2017), examine and reimagine energy infrastructures (Winthereik et al., 2019), or host seminars and "walkshops" that adopt an experimental approach to research in the wild (Mol, n.d.; Wickson et al., 2015). Here, walking becomes a technique for mobilizing collective inquiry while speculating about the possibilities for environmental transformation. These forms of walking and researching can also become integral to reconstituting engagements with environments.

Yet this is not to cast a simple binary between individual and collective walking, because solitary walks can also call on collective memory and inhabitation while also serving as witness to changes in land and living practices, such as Raja Shehadeh's (2007) walks in Palestine over many years. What such collective walking practices bring to the foreground is a greater attention to how movement takes place with others, including organisms and ecosystems. Walking becomes a way to craft experience and activate place (Lorimer, 2011). These processes of movement can crystallize subjects and relations to environments and other entities, even in their absence, or as hauntings (Toso et al., 2020).

When Indigenous communities living in Atacama desert environments describe their process of becoming a desert that walks, the usual conditions of moving are thrown into question. By walking 350 kilometers to the capitol to protest mining practices, they activated their collective walk as more than a movement of multiple humans to the political center of commerce and national government. Even more, they walked as representatives of the desert - a desert that moved them, and moved them to action. In this way, they carried their responsibility for and attachment to the desert with them. Their experiences of the desert and of being desert inhabitants were not registering in the centers of governments, where policy makers cast decisions about resource extraction based on investment opportunities and detached facts about subsurface minerals. The Atacameño Indigenous leaders carried the desert with them as a way of life, memory, social movement, political engagement, and concern. Here, walking materializes overlooked relations. It also unfolds as a haunting (which can, quite literally, mean to walk as an otherworldly or shadowy inhabitation). As mentioned in the introduction, the desert traveled even farther, as it circulated through media outlets and news stories, videos and social media reports, as well as through ongoing extraction (Greenwood et al., 2020).

To story (and be storied by) environments as walking, to observe their movements and attend to how they travel, is then to reconstitute the possible formations and relations across subjects and environments. The forest that walks designates a practice of decentering the human as the locus of movement and action (Bawaka Country et al., 2015; Simpson, 2014; Watts, 2013). Such a practice tunes into how ecosystems and organisms travel, how their movements form shifting relations, and how these patterns turn up within different sensing practices that are not necessarily situated within a discrete body-place configuration (Ballestero, 2019; Gabrys, 2016). This could even be a way to rework colonial epistemic practices that place a particular kind of human at the center of knowledge practices and experiences, which typically hinge on a bifurcation of nature (Sundberg, 2014).

One possible thread of research would be to learn from different practices of how people, including forest dwellers, walk with environments and environments walk with them. Another thread would be to consider how the decentering of the human can generate different ways of understanding environmental movements. While these and multiple other threads intersect when considering the different perspectives on how the forest walks, I take up the second thread by turning in the next section of this essay to consider how digital technologies mobilize forests. I specifically consider how digital technologies organize ways of doing fieldwork that set environments in motion and that also demonstrate how environments are already in motion.

\section{Digital Fieldwork With the Forest That Walks}

Returning to the questions outlined in the introduction, this section considers not only the forest that walks but also how it could be possible to find other ways to walk with forests in a time when it can be difficult to walk in forests. The Smart Forests research project studies the increasing digitalization of forest environments and asks how these technologies are transforming relations with these spaces (Gabrys, 2020). One aspect of this research has been to consider how forests surface as different compositions within digital networks and infrastructures. A forest site could be designated as a biodiversity reserve, a carbon store, or a site of special scientific interest. Yet these designations require more than the bounded site to take on their distinct eco-social form. They also require policy documents and observation technologies, financial investments and political agreements, media campaigns and citizen engagement, and forest inhabitations and stories. Such forest sites could then be described as distributed networks (cf. Burrell, 2009; Kwon, 2002).

The movements of forests here potentially unfold not primarily as particular versions of humans moving through space but more through a distinct approach to digital fieldwork that considers how forest sites travel through technologies and data including remote sensing, web cameras, sensors, digital dashboards, participatory apps, and many other devices that document events in forest environments. By focusing on these devices, I do not suggest that humans 
are not present but rather that they are reconstituted through these digital engagements with the forest that walks. In a related study, Ballestero (2019) has considered how underground and inaccessible aquifers in Costa Rica become available to various forms of environmental management and attention through remote sensing. These technoscientific practices of "touching with light" render spaces that are out of sight and out of touch available to observation, albeit in particular ways that have distinct consequences for ways of life, politics, and governance.

Smart Forests then pose the dilemma of how to research these digital-environmental compositions through situated encounters. The forest could be a designated location. It could also be constituted within the data capture of remotesensing satellites. It could circulate through policy documents and white papers that mobilize data toward some form of protection. It could surface as transformed practices of observation and detection that filter through participatory monitoring technologies. And it could be present as an integral contributor to distinct ways of life.

Yet this dilemma further multiplies in a time of COVID-19 and ongoing geopolitical conflict. If researchers are located at some distance from forests, then they might be accessed through less proximate sensing practices. The conditions for experiencing field sites and for undertaking fieldwork - whether within forests, data centers, or digital infrastructures - can shift and filter through non-proximate locations. In this way, approaches to knowing and experiencing sites that require humans as the central and located entity for forming experiences and understanding are transformed. Here, (certain) humans are unable to access forests directly, and by extension are unable to form distinct types of "situated knowledges" (Haraway, 1998).

Practices such as fieldwork and walking can reinforce the sense that being in place is the best way to understand these locations. And these forms of research do generate experiences that cannot be replicated through less proximate forms of study. Yet the absence of researchers from sites can also dismantle the usual understanding of bodies in sites that lead to unexamined understandings of sensing and knowing. More distanced and digital fieldwork can also rework the binary delineations of online and offline worlds (Boellstorff, 2016).

There are many texts outlining how digital technologies can augment fieldwork: for instance, in the form of GPS, AR, and other digital tools (Martini, 2020; cf. Vannini \& Vannini, 2017). At the same time, digital ethnography is by now a well-established topic that in the time of COVID-19 has received heightened attention for its guide to interviewing, observing, and documenting human subjects and their social relations (Hjorth et al., 2017). However, digital fieldwork could also decenter the human both from in situ augmented research and from the topic of research. Forests are composed and circulating through webcams and acoustic sampling, satellite maps and sensor feeds, apps and platforms, Instagram accounts, and Twitter threads. These technologies differently distribute forest sites. They also surface particular ways of undertaking digital fieldwork from nonproximate locations. In the process, forests show up as walking in ways that might have been less evident if human researchers were the primary measure of movement and experience.

\section{Global Forest Watch}

One example of the digital compilations of forest sites and their movements is the GFW platform. As a long-standing and extensive public platform for forest data re-launched in 2014, GFW allows users to view multiple layers of forest data that document deforestation, wildfires, and reforestation. GFW is hosted by the World Resources Institute (WRI) in Washington, D.C., and includes more than 100 partners, including Agrosatélite, Astro Digital, Digital Globe, Google, NASA, and many other technology companies as well as development organizations. ${ }^{5}$ The forest turns up on this platform as a series of data sets presented in geo-spatial layers. Tree loss, fire alerts, and drivers of deforestation can be toggled on and off, compared with satellite base maps, and animated in time-series displays. Dashboards show where and when forest changes are occurring, whether at national and regional levels or through custom areas of interest.

Despite the remoteness of studying forest change through the GFW platform, the events displayed on the site are relatively instantaneous. Forest monitoring, as GFW emphasizes, is "designed for action." In this respect, its data and tools are meant to "empower people everywhere to better protect forests." Such action on forest change is organized through the ability "to monitor world's forests in near real-time." In other words, while not proximate in space, the site attempts to generate proximity in time.

With data sets such as the Global Land Analysis Discovery (GLAD) collections that focus especially on tropical and subtropical forest changes, GFW uses "cuttingedge algorithms, satellite technology and cloud computing" to support a series of tools, including dashboards and apps for tracking deforestation by country, receiving fire alerts, and analyzing supply chains. Changes in forests materialize on satellite and vector maps as patterns of vegetation moving across space and time. Time-series animations show green patches of forest carved into polygons for soybean cultivation, corridors for roadways, and blank rectangles for timber harvesting. Rather than study forest changes through a walk in the forest, instead forests walk across this platform through data sets, satellite traces, policy documents, and supply chain analysis. 
The alert is a key feature of this instantaneity, where deforestation data from Landsat 7 and 8 satellites are updated weekly, and fire data from NASA satellites and Visible and Infrared Scanner (or VIRS) data sets are updated daily. By setting up an account on the GFW platform, a user can receive alerts about specific areas. The stated intention of the platform is that government officials and law enforcement workers can keep track of and stop illegal activities, journalists can undertake more informed investigations, and companies can monitor supply chains more closely. But the alert also becomes a way to walk to and with the forest, albeit in a specific way, where reminders are sent to return to the site, take action, and observe the forest as it walks.

In addition to organizing action through instantaneity, the GFW platform generates distinct topologies and topographies of remoteness. Imagined users are not necessarily in situ, but at various degrees of remove from forests, whether they are sustainability managers overseeing supply chains, government officials, researchers, or local environmental officials. An introductory video explaining the GFW platform starts with the well-known question: "If a tree falls in the forest and nobody hears it, does it make a sound?" The platform is meant to provide a more proximate set of details about deforestation, even when users are remote from forest events. This is seen to be a way to make deforestation more legible, transparent, and actionable, where as the narrator to the introductory video notes, "So now if a tree falls in the forest, everyone hears it." The no-body that would be present in the forest to observe and walk with it is here replaced with digital presence that would make available forest events to "everyone" who are now able "to protect forests everywhere." Yet these digital structures could complicate environmental governance by making data seemingly easily available without attending to what data are excluded, and who is best placed and most able to act on forest changes (Goldstein \& Faxon, 2020).

Remoteness is, furthermore, a shared condition across multiple actors engaged with forests, from journalists to researchers and government officials. Indigenous communities are unevenly included in this diagram of action, which assumes distance and non-inhabitation as the basis for monitoring, setting up, and receiving alerts. At the same time, "local" people such as farmers and government officials would be able to receive alerts so as to locate sites of disturbance or take action based on deforestation and fire events. People "on the ground" then move in relation to the movements of forests, but this is a particular configuration of the forest that walks which is somewhat distinct from the desert protest walk discussed earlier. Digital technologies here organize and inform approaches taken to environments, which configure data as the basis to action. Yet as the Atacama example suggests, action can also be activated through other registers of environmental engagement that are not primarily or principally data-oriented.
This approach to remoteness and action took on even more concrete form with the arrival of COVID-19. In May 2020, GFW hosted a webinar to discuss the potential of its tools "in the new reality of remote work." In the absence of being able to visit field sites or undertake sustained fieldwork, GFW representatives noted that many of its tools could be used to gain an almost immediate sense of forest disturbance activities that could be occurring. These webinar hosts undertook a detailed walkthrough of the platform, showing how users could keep track of specific forest areas and track their movements and changes over time by using different data layers, satellite base maps, and custom alerts. ${ }^{8}$ The dashboard and the map here become the interface that organizes forest encounters and experience. Rather than fieldworkers walking through forests, forests walk to them through digital tools and configurations of experience.

The walkthrough becomes another way of walking within digital environments. Light et al. (2018) describe the "walkthough method" as a forensic investigation into apps and the assumptions they code into user experience. By using a step-by-step practice of walking through every stage of an app or platform, one can encounter the assumed user(s) to whom the site is directed, the constitution of social worlds that one is meant to inhabit, and the forms of action that are embedded as self-evident and necessary. These operations configure actions, relations, and socialpolitical worlds. At the same time, apps and platforms are not worlds unto themselves, and they program and activate particular relations and effects. Regular alerts received about fires and deforestation can require further investigation into forest movements and changes. Yet this forest walks in different ways depending upon who walks with it - whether remote researcher, journalist, international non-governmental organization (NGO), local government official or farmer, or Indigenous community member. The necessary chain of actions to address fires for clearing land in Brazil or Cambodia is not available equally to everyone everywhere, despite the universality and transparency of data that the GFW platform presents.

Digital fieldwork here performs distinct distributions of sites - as networked, distant, layered, scalable, and actionable. Digital tools such as the GFW platform and apps rework sites for environmental governance. Along the way, they also reconstitute sites through different distributions and forms of sites and sensing that span from the remote to the instantaneous. Remote sensing here activates particular users to walk with the forest, to notice the forest that walks, and to take actions in relation to these distinctly configured sites.

Yet how or whether people are moved to act because of forest changes is another question-because this form of digital fieldwork and remote walking could generate or constrain possibilities for moving with forests in ways that are more just if they do not walk toward a pluriversality of 
ways for engaging with forests. As Burrell (2009) notes, with digital ethnography and networked sites, the point is less to attempt to study sites in their assumed entirety, and instead to work through "entry points" rather than "bounded locations" (p. 190). If, as Burrell further notes, sites are composed of and changed by multiple networks, then the entry points for engaging with sites must necessarily exceed one platform-however all-encompassing its data sets appear to be. The forest that walks does so not just through remote-sensing data sets. It also travels through ways of life that can be distinct from digital modes of environmental governance, or that work toward practices for computing otherwise (Amrute \& Murillo, 2020).

\section{Conclusion: Places in Motion}

In contrast to more human-centered approaches to walking, this discussion lingers with the forest that walks. The motivation for this shift in focus is to at once decenter the human from walking narratives and, in so doing, to open up multiple different registers for how walking forests could be encountered, observed, and potentially narrated. By decentering the human - or certain types of humans - from walking, sites as moving compositions of more-than humans potentially become more present. At the same time, the figure of the moving (and sensing) human is necessarily recast through its initial and apparent absence. This leads to a consideration of who is in the forest and who walks with the forest. Different degrees of proximity to and remoteness from forests can suspend and transform encounters with sites. The forest here could be a situated set of encounters, but it could also be a traveling experience and set of narratives that animate different eco-social movements.

Forests move, and they also move others to walk with them. These movements show up in environmental actions and campaigns against deforestation. They also surface in digital platforms that would keep a constant watchful eye over the ongoing loss of forests. In a time of COVID-19, when forest visits could be difficult or impossible for some people, remote encounters with forests as distributed sites and networks become increasingly important. Forest managers, government officials, corporate sustainability personnel, and local farmers encounter forests differently through geo-spatial data and near real-time alerts. These become tools of environmental governance that also attempt to walk with forests when walking in forests can be more challenging. At the same time, these tools operate within certain epistemic and ontological regimes that do not necessarily accommodate Indigenous ways of life and experiences of walking with forests. As Sundberg (2014) notes, walking with is a way of walking toward more pluriversal worlds and encounters (see also Zapatista Army of National Liberation, 1996). Could a digital dashboard accommodate Indigenous experiences of the forest that walks, or would different experiences, encounters, and technologies be necessary to enable this pluriversality? How might Indigenous experiences of how they are the forest that walks register as significant for addressing environmental change?

Places are in motion, as Vizenor and Lee $(1999$, p. 61) note, and storytelling - here in a digital modality - becomes a way to constitute place, presence, stories, and the storier. Walking with and alongside through stories and media is a way of experiencing sites. However, it is also a way in which sites go walking. Digital technologies reconstitute subjects and environments, especially in the context of mass deforestation, climate change, and extractivism-in some cases enabling or causing these same events. Such moving compositions of forest sites can differently inform environmental governance. The forest walks through these multiple events, and multiple entities walk with forests. Digital tools present one way of considering how to walk when absent from sites. But they also point to the need to develop walking worlds that are more open to multiple stories and forest inhabitations. Rather than propose these digital tools as solutions to engaging with the forest that walks in a time of remote fieldwork, this article instead considers how such technologies reconstitute forests and forest engagements in ways that have direct consequences for how to tune into moving forests, and to walk with forests and other forest inhabitants.

\section{Acknowledgment}

Thanks are due to Stephanie Springgay and Sarah Truman for their editorial contributions to this text (and special issue), and to Sara Yazdani and the organizers and participants of the "Parallel Ecologies" virtual symposium, where this work was presented.

\section{Declaration of Conflicting Interests}

The author(s) declared no potential conflicts of interest with respect to the research, authorship, and/or publication of this article.

\section{Funding}

The author(s) disclosed receipt of the following financial support for the research, authorship, and/or publication of this article: This project has received funding from the European Research Council (ERC) under the European Union's Horizon 2020 Research and Innovation Program (Grant Agreement No. 866006).

\section{ORCID iD}

Jennifer Gabrys (iD https://orcid.org/0000-0001-5545-2459

\section{Notes}

1. The Grenfell Tower fire broke out on June 14, 2017, in London. Community groups, including Justice4Grenfell, have organized and held silent walks on the 14th of every month, as well as at the anniversary point of the fire. See Justice4Grenfell, Silent Walk Update, https://justice4grenfell. 
org/541/; Grenfell United, Grenfell Silent Walk marking 25 months, https://www.youtube.com/watch?v=N0kZueGmuPs; and BBC News, Grenfell Tower Fire: Silent Walk Marks First Anniversary (June 14, 2018; https://www.bbc.co.uk/news/ uk-44475913).

2. As writers note on The Guardian landing page for this video, "The Atacama in northern Chile is the driest desert in the world, and may be the oldest. It also holds $40 \%$ of the world's lithiuman essential ingredient in the rechargeable batteries used in green technology. Indigenous leaders and scientists say Chile's plans to feed a global green energy boom with Atacama lithium will kill the desert. As violent protests rock the country, they are fighting for the mining to stop" (see Greenwood et al., 2020).

3. Smart Forests, https://smartforests.net/.

4. For example, see Our World in Data, Deforestation and Forest Loss (https://ourworldindata.org/deforestation).

5. Global Forest Watch (GFW; https://www.globalforestwatch.org/) and 3 Sided Cube, A Conservation App to Save Our Forests (https://3sidedcube.com/projects/global-forestwatch-deforestation-app/).

6. GFW (https://www.globalforestwatch.org/).

7. GFW, Monitoring forests in Near Real Time (February 20, 2014; https://www.youtube.com/watch?v=1TG-0brb98I; https://3 sidedcube.com/projects/global-forest-watchdeforestation-app/).

8. GFW, Utilizing GFW Tools in the New Reality of Remote Work (May 26, 2020; https://www.youtube. $\mathrm{com} /$ watch $? \mathrm{v}=4 \mathrm{iGatApnKNk} \&$ list $=$ PLh91 $\mathrm{mManXhdk}$ hqW_Cl6mCPRjUko_EgYfF\&index=12).

\section{References}

Amrute, S., \& Murillo, L. F. R. (2020). Introduction: Computing in/ from the South. Catalyst: Feminism, Theory, Technoscience, $6(1), 1-23$.

Ballestero, A. (2019). Touching with light, or, how texture recasts the sensing of underground water. Science, Technology, \& Human Values, 44(5), 762-785.

Bates, C., \& Rhys-Taylor, A. (Eds.). (2017). Walking through social research. Routledge.

Bawaka Country, Wright, S., Suchet Pearson, S., Lloyd, K., Burarrwanga, L., Ganambarr, R., Ganambarr-Stubbs, M., Ganambarr, B., \& Maymuru, D. (2015). Working with and learning from Country: Decentring human author-ity. Cultural Geographies, 22(2), 269-283.

Benjamin, W. (1999). The arcades project (H. Eiland \& K. McLaughlin, Trans.). Belknap Press of Harvard University Press.

Boellstorff, T. (2016). For whom the ontology turns: Theorizing the digital real. Current Anthropology, 57(4), 387-407.

Bullard, R. (1990). Dumping in Dixie: Race, class and environmental quality. Westview Press.

Burrell, J. (2009). The field site as a network: A strategy for locating ethnographic research. Field Methods, 21(2), 181-199.

Cadogan, G. (2016, July). Walking while Black. Literary Hub. http://lithub.com/walking-while-black/

Edensor, T. (2000). Walking in the British countryside: Reflexivity, embodied practices and ways to escape. Body \& Society, 6(3-4), 81-106.
Gabrys, J. (2012). Becoming urban: Sitework from a moss-eye view. Environment and Planning A, 44, 2922-2939.

Gabrys, J. (2016). Program earth: Environmental sensing technology and the making of a computational planet. University of Minnesota Press.

Gabrys, J. (2017). Air walk: Monitoring pollution and experimenting with speculative forms of participation. In C. Bates \& A. Rhys-Taylor (Eds.), Walking through social research (pp. 144-161). Routledge.

Gabrys, J. (2020). Smart Forests and data practices: From the Internet of Trees to planetary governance. Big Data \& Society, $7(1), 1-10$.

Gabrys, J. (forthcoming). Citizens of worlds: Open-air toolkits for environmental struggle. University of Minnesota Press.

Goldstein, J. E., \& Faxon, H. O. (2020). New data infrastructures for environmental monitoring in Myanmar: Is digital transparency good for governance? Environment and Planning E: Nature and Space. Advance online publication. https://doi. org/10.1177/2514848620943892

Greenwood, P., Cherry, C., Minguell, M., Phillips, P., Topham, L., \& McVeigh, T. (2020, February 18). Will green technology kill Chile's deserts? [Video]. The Guardian. https://www.theguardian.com/global-development/video/2020/feb/18/willgreen-technology-kill-chiles-deserts-video

Gros, F. (2014). A philosophy of walking (J. Howe, Trans.). Verso. (Original work published 2009)

Haraway, D. (1988). Situated knowledges: The science question in feminism and the privilege of partial perspective. Feminist Studies, 14(3), 575-599.

Hjorth, L., Horst, H., Galloway, A., \& Bell, G. (Eds.). (2017). The Routledge companion to digital ethnography. Routledge.

Houston, D. (2013). Environmental justice storytelling: Angels and isotopes at Yucca Mountain, Nevada. Antipode, 45(2), 417-435.

Kwon, M. (2002). One place after another: Site-specific art and locational identity. MIT Press.

Lessard, S., Kootenay, I., Whiskeyjack, F., Chung, S., Clandinin, J., \& Caine, V. (2021). Working with Indigenous elders in narrative inquiry: Reflections and key considerations. Qualitative Inquiry, 27(1), 28-36.

Light, B., Burgess, J., \& Duguay, S. (2018). The walkthrough method: An approach to the study of apps. New Media \& Society, 20(3), 881-900.

Lorimer, H. (2011). New forms and spaces for studies of walking. In T. Cresswell \& P. Merriman (Eds.), Geographies of mobilities: Practices, spaces, subjects (pp. 19-34). Ashgate.

Martini, N. (2020). Using GPS and GIS to enrich the walk-along method. Field Methods, 32(2), 180-192.

Mol, A. (n.d.). The walking seminar. http://walkingseminar. blogspot.com

O'Rourke, K. (2013). Walking and mapping: Artists as cartographers. MIT Press.

Pezzullo, P. C. (2007). Toxic tourism: Rhetorics of pollution, travel, and environmental justice. The University of Alabama Press.

Powell, A. (2018). The data walkshop and radical bottom-up data knowledge. In H. Knox \& D. Nafus (Eds.), Ethnography for a data-saturated world (pp. 212-232). University of Manchester Press. 
Shehadeh, R. (2007). Palestinian walks: Notes on a vanishing landscape. Profile Books.

Simpson, L. B. (2014). Land as pedagogy: Nishnaabeg intelligence and rebellious transformation. Decolonization: Indigeneity, Education \& Society, 3(3), 1-25.

Springgay, S., \& Truman, S. E. (2017). Walking methodologies in a more-than-human world: WalkingLab. Routledge.

Springgay, S., \& Truman, S. E. (2019, May). Walking researchcreation: QTBIPOC temporalities and world makings. MAI: Feminism \& Visual Culture. https://maifeminism.com/walking-research-creation-qtbipoc-temporalities-and-world-makings/

Sundberg, J. (2014). Decolonizing posthumanist geographies. Cultural Geographies, 21(1), 33-47.

Toso, T., Spooner-Lockyer, K., \& Hetherington, K. (2020). Walking with a ghost river: Unsettling place in the Anthropocene. Anthropocenes-Human, Inhuman, Posthuman, 1(1), 3. https://doi.org/10.16997/ahip.6

Vannini, P., \& Vannini, A. (2017). Wild walking: A twofold critique of the walk-along method. In C. Bates \& A. RhysTaylor (Eds.), Walking through social research (pp. 179195). Routledge.

Vizenor, G., \& Lee, R. A. (1999). Postindian conversations. University of Nebraska Press.

Watts, V. (2013). Indigenous place-thought and agency amongst humans and non-humans (First Woman and Sky Woman go on a European tour!). Decolonization, Indigeneity, Education \& Society, 2(1), 20-34.

Wickson, F., Strand, R., \& Kjølberg, K. L. (2015). The walkshop approach to science and technology ethics. Science and Engineering Ethics, 21, 241-264.

Winthereik, B. R., Maguire, J., \& Watts, L. (2019). The energy walk: Infrastructuring the imagination. In J. Vertesi \& D. Ribes (Eds.), digitalSTS: A field guide for science \& technology studies (pp. 349-364). Princeton University Press.

Zapatista Army of National Liberation. (1996). Fourth declaration of the Lacandon jungle. http://struggle.ws/mexico/ezln/ jung4.html

Ziewitz, M. (2017). A not quite random walk: Experimenting with the ethnomethods of the algorithm. Big Data \& Society, 4(2), $1-13$.

\section{Author Biography}

Jennifer Gabrys is Chair in Media, Culture and Environment in the Department of Sociology at the University of Cambridge. She leads the Planetary Praxis research group and is principal investigator on the European Research Council (ERC)-funded project, "Smart Forests: Transforming Environments Into Social-Political Technologies." Her newest book, Citizens of Worlds: Open-Air Toolkits for Environmental Struggle, is forthcoming from University of Minnesota Press. Her work can be found at planetarypraxis.org. 